\title{
A Holistic Approach to Measure Organizational Readiness for Knowledge Management
}

\author{
Mohamed Jalaldeen Mohamed Razi ${ }^{1}$, Nor Shahriza Abdul Karim², Abdul Rahman Ahmad Dahlan ${ }^{3}$, Noor Azian Mohamad Ali $^{4}$ \\ Kulliyah of Information and Communication Technology, International Islamic University Malaysia. Malaysia ${ }^{1,3,4}$ \\ Faculty of Computer and Information Science, Prince Sultan University, Kingdom of Saudi Arabia ${ }^{2}$
}

\begin{abstract}
Management of organizational Knowledge is considered crucial in the present knowledge era. As a result, organizational readiness for knowledge management (KM) has been studied comprehensively from diverse viewpoints lately. KM enablers such as organizational culture, organizational structure and information technology infrastructures, and organizational members' perception towards KM are assumed to be the predictors of KM readiness. Nevertheless, those dimensions could be part of KM readiness rather than just merely being its predictors considering the inevitable nature of those variables for KM implementation. Accordingly, the current study hypothesis that these factors with behavioral intention of organizational members form a holistic dimension of organizational readiness for KM. To verify this claim a questionnaire based survey was conducted among 313 executives in the Sri Lankan telecommunication industry. To validate the research instruments used a first order measurement model was formulated using AMOS version 16. Then, to test hypotheses a second order analysis was performed. The indices for model fit are good and the structural coefficients are significant showing the data fit to the model. Hence, the present work recommends that the KM enablers, organizational members' perception and their behavioral intentions can be the dimensions of organizational readiness for KM.
\end{abstract}

Keywords: Knowledge Management, Organizational Readiness, KM enablers, SECI 


\section{INTRODUCTION}

Evaluation of organizational readiness for knowledge management $(\mathrm{KM})$ process implementation is advised before taking initiatives for implementation ${ }^{1}$ as it needs considerable determination with a substantial monetary implications $^{2}$, and necessitate modifications in the conduct of any organization and attitudinal modifications in the conduct of organizational members ${ }^{3}$. Therefore, large numbers of research efforts ${ }^{1,2,4-15}$ have been done to study organizational readiness for KM recently. Most of them considered organizational members' behavioral intention $^{9-15}$ and positive attitudes ${ }^{1-4}$ to $\mathrm{KM}$ as the organizational readiness for $\mathrm{KM}$ and deliberated $\mathrm{KM}$ supportive organizational factors (KM Enablers) as the predictors of intention towards KM practices.

*Email Address: razimjm@jiium.edu.my

While some other studies considered perceived availability of $\mathrm{KM}$ supportive organizational factors ${ }^{7,16}$ and perceived importance and actual implementation of KM supportive organizational factors ${ }^{6}$ as the organizational readiness for KM. Meantime, organizational members perception towards $\mathrm{KM}$; perceived usefulness and perceived ease of use also been considered as the predictors of KM initiatives ${ }^{2,13}$.

However, the potentials of KM enablers, perception towards $\mathrm{KM}$ and behavioral intentions indicate that they might be the dimensions of organizational readiness for KM. The current effort attempts to validate this hypothesis.

$\mathrm{KM}$ enablers ${ }^{17}$ demonstrate the socio-technical nature of KM by focusing on organizational culture, organizational structure, and IT infrastructure. Organizational culture reflects the norms and beliefs that guide the behavior of the organization's members ${ }^{18}$. Existence of an appropriate culture that encourages people to create and share knowledge within an organization is vital for KM implementation. The organizational culture symbolized in this study by trust ${ }^{19}$, learning ${ }^{17,20}$, knowledge centered business strategy ${ }^{6}$, and management support ${ }^{2 \mathrm{P}}$.

Organizational structure means the rules, policies, procedures, and processes, hierarchy of reporting relationships, incentive systems, and departmental boundaries that organize tasks within the firm ${ }^{22}$. Decentralization $^{17,20}$, and KM oriented rewarding system ${ }^{2 i}$ would be considered to measure organizational structure.

Information technology (IT) infrastructure includes data processing, storage, and communication technologies and systems $^{18}$. IT infrastructure assists to KM in numerous ways ${ }^{22}$ and IT is broadly used to link people and aids conversations ${ }^{17}$ that would help knowledge creation and sharing. IT support ${ }^{17,20}$ and ICT use ${ }^{21}$ would be considered to measure IT infrastructure.

There are theories/models to explain the organizational members" behavioral intention. Critical review of these models ${ }^{23,24}$ indicate that perceived usefulness and perceived ease of use are the main predictors of behavioral intention. Thus these variables would be considered to measure organizational members' perception towards KM.

Different measures have been used to assess the organizational members' behavioral intention of towards KM. Some of the studies focused only on knowledge sharing intention ${ }^{10-15}$ while some other studies ${ }^{2,25}$ considered knowledge creation and sharing intention. They have measured it using SECI, the origin of knowledge creation theory ${ }^{26}$. Nonaka ${ }^{26}$ suggests four diverse means of knowledge conversion; tacit knowledge to tacit knowledge (socialization), from explicit knowledge to explicit knowledge (combination), from tacit knowledge to explicit knowledge (externalization), and from explicit knowledge to tacit knowledge (internalization). An effort ${ }^{25}$ has been made to verify the SECI as dimension of behavioral intention to KM. Therefore SECI will be considered as the measurement of behavioral intention.

\section{PREVIUOS STUDIES}

Organizational readiness for $\mathrm{KM}$ has been continuously studied by number of researchers ${ }^{1,2,4-7,9-16}$ from different perspectives. Some studied ${ }^{1,4,5}$ from the change management viewpoint while some others measured it by examining the existence of $\mathrm{KM}$ supportive organizational factors ${ }^{7,9,16}$ and by assessing the perceived importance and actual implementation of KM associated factors ${ }^{6}$. Some others arranged variables that support KM implementation'. Meantime, other researchers tried to evaluate behavioral intention of organizational members' to $\mathrm{KM}^{2,10-14}$.

The literature review of previous studies on organizational readiness for KM reveals that $\mathrm{KM}$ enablers, organizational members' perception towards $\mathrm{KM}$ and behavioral intention has been considered as dimensions of organizational readiness for KM separately or partially. They fail to reflect them all in one study. Nevertheless, the importance of these dimensions demands a study into the effect to examine them in a holistic manner. Therefore, this study embarked to this effect.

\section{DATA COLLECTION AND DATA ANALYSIS}

A self-administered questionnaire was used to collect data from 313 executives from different gender, different age group, and with different work experience, in the Sri Lankan telecommunication industry. Please refer to the Appendix A. for questionnaire items. The executives were requested to specify (on a seven-point Likert scale ranging from "strongly disagree" to "strongly agree") their level of agreements to the statements.

A first order CFA model was formulated using AMOS version 16. The dimensions were denoted as correlated first-order factors. Summated scales values were used for each variable. The results confirmed that all observed variables, excluding "decentralization", loaded with factor loading and SMC higher than of $0.60^{27}$ and $0.40^{28}$ respectively. However, in the analysis, "decentralization" 
was used to avoid one factor observed variable issue. Table I shows the summary results of the first order CFA model.

\section{Table.1. Properties of Measurement}

\begin{tabular}{|c|c|c|c|c|c|}
\hline Constructs & Item description & Mean & Std. Dev & \begin{tabular}{|l|} 
Factor \\
loadings
\end{tabular} & SMC \\
\hline \multirow{5}{*}{$\begin{array}{l}\text { Organization } \\
\text { Culture }\end{array}$} & & & & & \\
\hline & Trust & 5.16 & 0.95 & 0.71 & 0.51 \\
\hline & Learning & 4.89 & 1.29 & 0.81 & 0.65 \\
\hline & Bus. Strategy & 5.02 & 1.04 & 0.86 & 0.75 \\
\hline & Mgt. Support & 4.76 & 1.41 & 0.78 & 0.61 \\
\hline \multirow{3}{*}{$\begin{array}{l}\text { Organization } \\
\text { Structure }\end{array}$} & & & & & \\
\hline & Decentralization & 3.88 & 1.44 & 0.57 & 0.33 \\
\hline & Rewards & 3.44 & 1.51 & 0.71 & 0.50 \\
\hline \multicolumn{6}{|c|}{ IT- Infrastructure } \\
\hline & IT Support & 5.16 & 1.11 & 0.74 & 0.55 \\
\hline & ICT Use & 5.19 & 1.13 & 0.71 & 0.51 \\
\hline \multirow{3}{*}{$\begin{array}{l}\text { Individual } \\
\text { Perception }\end{array}$} & & & & & \\
\hline & \begin{tabular}{|l|} 
Performance \\
Expectancy of \\
KM \\
\end{tabular} & 5.61 & 0.90 & 0.84 & 0.71 \\
\hline & $\begin{array}{l}\text { Effort Expectancy } \\
\text { of KM }\end{array}$ & 5.54 & 0.79 & 0.77 & 0.60 \\
\hline \multicolumn{6}{|l|}{ SECI } \\
\hline & Socialization & 5.45 & 0.79 & 0.76 & 0.58 \\
\hline & Externalization & 5.41 & 0.72 & 0.84 & 0.70 \\
\hline & Combination & 5.07 & 0.94 & 0.75 & 0.56 \\
\hline & Internalization & 5.16 & 1.11 & 0.77 & 0.59 \\
\hline
\end{tabular}

The convergent validity was examined considering average variance extracted (AVE) and composite reliability (CR). Please see table 2. Except "organizational structure", other all constructs' AVE and CR values are above the threshold value of 0.5 and 0.7 respectively. Accordingly AVE scores are; organizational culture (0.63), organizational structure $(0.41)$, IT infrastructure $(0.53)$, individual perception (0.65), and Behavioral intention SECI (0.61). CR values are: organizational culture (0.87), organizational structure $(0.58)$, IT infrastructure $(0.69)$, individual perception (0.78), and Behavioral intention SECI (0.86). Since the AVE values are above 0.5 and the correlation values are below $0.84^{30}$, the discriminant validly and convergent validity are achieved.

Table.2 Mean, Std. Dev., AVE, \& Squared Correlation Properties of Measurement

\begin{tabular}{|c|c|c|c|c|c|c|c|c|}
\hline & Mean & $\begin{array}{l}\text { Std. } \\
\text { Dev. }\end{array}$ & $\begin{array}{l}\text { Comp } \\
\text {.Rel. }\end{array}$ & 1 & 2 & 3 & 4 & 5 \\
\hline $\begin{array}{l}\text { 1. Organizational } \\
\text { Culture }\end{array}$ & 6.95 & 0.96 & 0.87 & 0.63 & & & & \\
\hline $\begin{array}{l}\text { 2. Organizational } \\
\text { Structure }\end{array}$ & 3.66 & 1.23 & 0.58 & 0.39 & 0.41 & & & \\
\hline 3. IT- Infrastructure & 5.18 & 1.01 & 0.69 & 0.67 & 0.42 & 0.53 & & \\
\hline $\begin{array}{l}\text { 4. Individual } \\
\text { Perception }\end{array}$ & 5.57 & 0.77 & 0.78 & 0.30 & 0.11 & 0.46 & 0.65 & \\
\hline $\begin{array}{l}\text { 5. Behavioral } \\
\text { Intention - SECI }\end{array}$ & 5.34 & 0.66 & 0.86 & 0.23 & 0.07 & 0.35 & 0.60 & 0.61 \\
\hline
\end{tabular}

Measurements were validated using first-order measurement model by examining the fitness of indices. Accordingly, $\chi 2=104.214(\mathrm{p}<0.05)$, and normed $\chi 2=$ 2.449 , which are considered adequate ${ }^{29}$. As these are not enough to confirm the model $\mathrm{fit}^{31}$, other indicators were also measured. Accordingly, GFI $=0.954, \mathrm{AGFI}=0.927$, $\mathrm{NFI}=0.951, \mathrm{RFI}=0.933, \mathrm{IFI}=0.982, \mathrm{TLI}=0.974, \mathrm{CFI}=$ 0.98 , RMSEA $=0.043$, PCLOSE $=0.758$, and RMR $=0.048$ which are in the acceptable range ${ }^{32,33}$.

To achieve the objective of this effort, that is to validate whether the KM enablers, individual perception and behavioral intention (SECI) are the dimensions of organizational readiness for $\mathrm{KM}$, a second-order model was formulated. Accordingly, the indices are; $\chi 2=$ $176.676(\mathrm{p}<0.05), \mathrm{GFI}=0.921, \mathrm{AGFI}=0.883, \mathrm{NFI}=$ 0.918, RFI $=0.895$, IFI $=0.949$, TLI $=0.934$, CFI $=$ 0.949, RMSEA $=0.069$, PCLOSE $=0.008$, and RMR $=0.075$.

As shown in Figure. 1, the structural coefficients are significant (at p-value 0.01); Organizational Culture 0.81, Organizational structure 0.64, IT infrastructure" 0.95 , perception 0.76 and SECI 0.68. Similarly, $\mathrm{R}^{2}$ value for each construct are; Organizational Culture 0.66, Organizational structure 0.41 , IT infrastructure" 0.89 , perception 0.57 and SECI 0.46, that suggests the model is fit to the data. Hence, the five dimensions considered in this study might be used to measure the organizational readiness for $\mathrm{KM}$.

\section{CONCLUSION}

The findings suggest that the KM enablers such as organizational culture (mutual trust among organizational members, organizational learning culture, KM oriented business strategy, top management support), organizational structure (decentralized decision making, and $\mathrm{KM}$ oriented performance based rewards), and IT infrastructure (availability of IT facility, and use of those facility), individual perception (performance expectancy of $\mathrm{KM}$, and effort expectancy of $\mathrm{KM}$ ), and organizational members' behavioral intention towards KM (SECI) are fundamental part of organizational readiness for KM. They are not simply the predictors of the concept. Accordingly, the practitioners may work towards to make sure the availability of good organizational climate with these elements. However, to make the finding robust more empirical investigations are needed for different contexts.

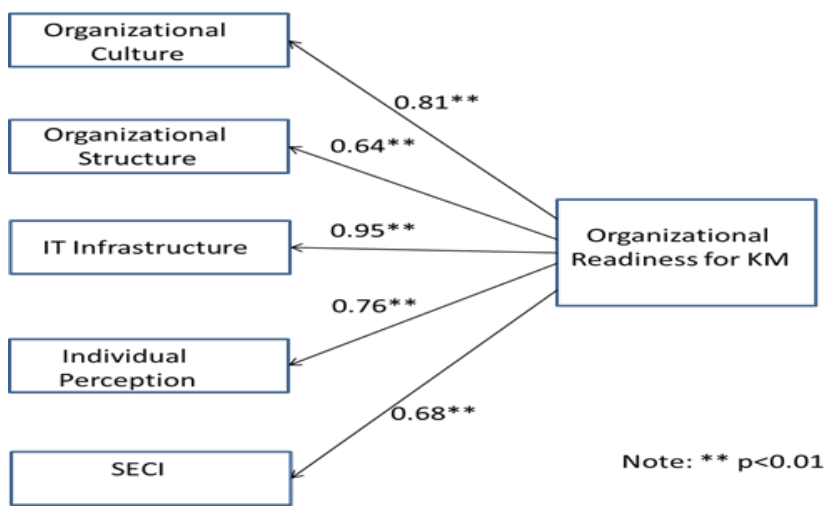


Fig.1. Analysis Results

\section{Appendix A. Survey instruments \\ Trust $^{19}$}

I believe colleagues in my organization are honest and reliable.

I believe colleagues in my organization treat others reciprocally

I believe colleagues in my organization are knowledgeable and competent in their area.

I believe colleagues in my organization will act towards the best interest of the organizational goals.

Learning $^{17-20}$

My organization provides various formal training

My organization provides opportunities for informal individual development other than formal training.

My organization encourages people to attend seminars, symposia, and so on.

My organization provides various programs such as clubs and community gatherings.

I am satisfied with the contents of job training or self-development programs.

Business Strategy ${ }^{6}$

I understand the importance of knowledge.

My organization formulates strategic plans for knowledge creation and sharing.

My organization has specific objectives for knowledge creation and sharing.

My organization's mission statement reflects the importance of knowledge creation and sharing

Management Support ${ }^{21}$

My senior managers always support the knowledge creation and sharing initiatives.

My senior managers provide necessary help and resources for knowledge creation and sharing initiatives.

My senior managers are keen to see my involvement in knowledge creation and sharing initiatives.

Decentralization $^{17-20}$

I can make decisions without approval.

I am encouraged to make my own decisions.

I do not need to refer to someone else.

I can take action without a supervisor.

Reward $^{21}$

My organization provides higher salary in return for my contribution to knowledge creation and sharing.

My organization provides higher bonus in return for my contribution to knowledge creation and sharing.

My organization provides promotions in return for my contribution to knowledge creation and sharing.

My organization provides increased job security in return for my contribution to knowledge creation and sharing.

IT Support ${ }^{17-20}$

My organization provides IT support for collaborative works regardless of time and place.

My organization provides IT support for communication among colleagues in my organization.

My organization provides IT support for simulation and prediction.

My organization provides IT support for systematic storing of valuable records.

My organization provides IT support for searching necessary information and sharing it with others
ICT use $\operatorname{Lin}^{21}$

I use electronic storage (such as online data base and data warehousing) extensively to access knowledge.

I use knowledge networks (such as groupware, intranet, virtual communities, etc.) to communicate with colleagues.

I use the technology to share knowledge with colleagues in my organization.

I use the technology to share knowledge with other persons outside the organization.

Performance Expectancy of $\mathrm{KM}^{23}$

I would find creation and sharing of knowledge useful in my job.

Creation and sharing of knowledge would enable me to accomplish task more quickly.

If I involve with knowledge creation and sharing initiatives, it will increase my chances of getting a better pay.

Creation and sharing of knowledge would enhance my productivity

Effort Expectancy of $\mathrm{KM}^{23}$

My role in knowledge creation and sharing process would be clear and understandable.

It would be easy for me to become skillful in knowledge creation and sharing initiatives.

Learning the initiatives of creation and sharing of knowledge would be easy for me.

I would find the involvement in the process of knowledge creation and sharing is easy.

Socialization $^{17,20}$

I intend to be involved in gathering information and experiences from others within my organization.

I intend to be involved in sharing information and experiences with others within my organization.

I intend to be engaged in dialogue with competitors.

I intend to be involved in finding new strategies and opportunities inside the organization.

I intend to be involved in creating a work environment that allows colleagues to understand the craftsmanship and expertise.

Externalization $^{17-20}$

I intend to be involved in creative dialogues with colleagues.

I intend to use deductive (top down) and inductive (bottom up) thinking for strategy formulation.

I intend to use metaphors (images/description) in dialogue for concept creation.

I intend to exchange various ideas with colleagues.

I intend to provide subjective opinions in dialogues.

Combination $^{17-20}$

I intend to use published literature, computer simulation and forecasting to formulate strategies.

I intend to create manuals and documents on product and services.

I intend to create databases on product and services.

I intend to build up materials by gathering literature and technical information.

I do not intend to transfer newly created concepts to my colleagues

Internalization $^{17-20}$

I intend to be involved in liaising activities with other departments by developing cross functional teams.

I intend to be involved in setting teams as a model for conducting experiments, and sharing results with entire departments.

I intend to be involved in searching and sharing new values and thoughts with colleagues.

I intend to share and try to understand management vision through communications with colleagues. 


\section{REFERENCES}

[1] D. Holt, S. Bartczak, S. Clark, and M. Trent, "The development of an instrument to measure readiness for knowledge management," Knowledge Management Research \& Practice, vol. 5, pp. 75-92, 2007.

[2] N. S. A. Karim, M. J. M. Razi, N. Mohamed, and L. M. Abdullah, "Influencial Factors of KM Process Adoption: A Socialtechnological Based Approach," International Journal of Innovation and Business Strategy, vol. 01, pp. 95-102, 2012.

[3] C. E. Siemieniuch and M. A. Sinclair, "A framework for organisational readiness for knowledge management," International Journal of Operations \& Production Management, vol. 24, pp. 79-98, 2004.

[4] A. Shirazi and S. Mortazavi, "Factors affecting employees' readiness for knowledge management," European Journal of Economics, Finance and Administrative Sciences, vol. 7, 2011.

[5] F. H. Rusly, J. L. Corner, and P. Sun, "Positioning change readiness in knowledge management research," Journal of Knowledge Management, vol. 16, pp. 329-355, 2012.

[6] C. Wei, C. Choy, and W. Yew, "Is the Malaysian telecommunication industry ready for knowledge management implementation?," Journal of Knowledge Management, vol. 13, pp. 69-87, 2009.

[7] N. D. Mamaghani, R. Samizadeh, and F. Saghafi, "Evaluating the readiness of Iranian research centers in knowledge management," American Journal of Economics and Business Administration, vol. 3, p. 203, 2011.

[8] E. Jandaghi, G. Jandaghi, H. R. Irani, Z. S. Mousavi, and M. Davoodavabi, "Ranking the knowledge management enablers based on University Academic Members, Staff and Students using AHP Method," International Letters of Social and Humanistic Sciences, pp. 7-13, 2014.

[9] M. R. Sadeghi, S. M. Moghimi, and M. Ramezan, "Identifying and prioritizing of effective constructs in readiness of knowledge management implementation by using fuzzy analytic hierarchy process (AHP)," Journal of Knowledge-based Innovation in China, vol. 5, pp. 16-31, 2013.

[10] W. S. Chow and L. S. Chan, "Social network, social trust and shared goals in organizational knowledge sharing," Information \& Management, vol. 45, pp. 458-465, 2008.

[11] G. W. Bock, R. W. Zmud, Y. G. Kim, and J. N. Lee, "Behavioral intention formation in knowledge sharing: Examining the roles of extrinsic motivators, social-psychological forces, and organizational climate," MIS quarterly, pp. 87-111, 2005.

[12] C. W. Chen, M. L. Chang, C. P. Tseng, B. C. Chen, and Y. Y. C. Chang, "Critical human factor evaluation of knowledge sharing intention in Taiwanese enterprises," Human Factors and Ergonomics in Manufacturing \& Service Industries, vol. 23, pp. 95-106, 2013.

[13] S.-W. Hung and M.-J. Cheng, "Are you ready for knowledge sharing? An empirical study of virtual communities," Computers \& Education, vol. 62, pp. 8-17, 2013.

[14] Y. S. Hau, B. Kim, H. Lee, and Y.-G. Kim, "The effects of individual motivations and social capital on employees' tacit and explicit knowledge sharing intentions," International Journal of Information Management, vol. 33, pp. 356-366, 2013.

[15] A. Tamjidyamcholo, M. S. Bin Baba, H. Tamjid, and R. Gholipour, "Information security-professional perceptions of knowledge-sharing intention under self-efficacy, trust, reciprocity, and shared-language," Computers \& Education, vol. 68, pp. 223$232,2013$.
[16] E. Jandaghi, G. Jandaghi, H. R. Irani, Z. S. Mousavi, and M. Davoodavabi, "Evaluating the Readiness of Management Schools to Execute Knowledge Management," International Letters of Social and Humanistic Sciences, pp. 78-83, 2014.

[17] H. Lee and B. Choi, "Knowledge management enablers, processes, and organizational performance: An integrative view and empirical examination," Journal of management information systems, vol. 20, pp. 179-228, 2003.

[18] I. Becerra-Fernandez, A. Gonzalez, and R. Sabherwal, Knowledge Management: Challenges, 2004.

[19] S. Y. Choi, Y. S. Kang, and H. Lee, "The effects of socio-technical enablers on knowledge sharing: an exploratory examination," Journal of Information Science, vol. 34, p. 742, 2008.

[20] Y. C. Lee and S. K. Lee, "Capabilities, processes, and performance of knowledge management: A structural approach," Human Factors and Ergonomics in Manufacturing \& Service Industries, vol. 17, pp. 21-41, 2007.

[21] H. F. Lin, "Knowledge sharing and firm innovation capability: an empirical study," International Journal of Manpower, vol. 28, pp. 315-332, 2007.

[22] A. H. Gold, A. Malhotra, and A. H. Segars, "Knowledge management: An organizational capabilities perspective," Journal of management information systems, vol. 18, pp. 185-214, 2001.

[23] V. Venkatesh, M. G. Morris, G. B. Davis, and F. D. Davis, "User acceptance of information technology: Toward a unified view," MIS quarterly, pp. 425-478, 2003.

[24] F. D. Davis, "Perceived usefulness, perceived ease of use, and user acceptance of information technology," MIS quarterly, pp. 319-340, 1989.

[25] N. S. A. Karim, M. J. M. Razi, and N. Mohamed, "Measuring employee readiness for knowledge management using intention to be involved with KM SECI processes," Business Process Management Journal, vol. 18, pp. 777-791, 2012.

[26] I. Nonaka, "Organizational knowledge creation theory: a first comprehensive test," International Business Review, vol. 3, pp. 337-351, 1994.

[27] R. P. Bagozzi and Y. Yi, "On the evaluation of structural equation models," Journal of the Academy of Marketing Science, vol. 16, pp. 74-94, 1988.

[28] K. A. Bollen, Structural Equations with Latent Variables. New York, NY: Wiley, 1989.

[29] J. Hair, W. Black, B. Babin, R. Anderson, and R. Tatham, Multivariate Data Analysis Sixth Edition Pearson Education, 2006.

[30] A. Sekaran and J. R. G. Bougie, Research Methods for Business: A skill bulding approach. Chichester: Wiley, 2009.

[31] T. Raykow, A First Course in Structural Equation Modeling Mahwah, NJ: Lawrence Erlboum Associates, 2000.

[32] B. Tabachnick and L. Fidell, "Logistic regression," Using Multivariate Statistics. 4th ed. Boston, Mass: Allyn \& Bacon, pp. 517-581, 2001.

[33] B. M. Byrne, Structural Equation Modeling with AMOS. New York, NY.: Routledge, 2010. 